\title{
Quest for appropriate overcapacity in the fisheries industry
}

Kjærsgaard, Jens

Published in:

Socio-Economic Planning Sciences

DOI:

10.1016/j.seps.2009.12.001

Publication date:

2010

Document version

Publisher's PDF, also known as Version of record

Citation for published version (APA):

Kjærsgaard, J. (2010). Quest for appropriate overcapacity in the fisheries industry. Socio-Economic Planning Sciences, 44(3), 141-150. https://doi.org/10.1016/j.seps.2009.12.001 


\title{
Quest for appropriate overcapacity in the fisheries industry
}

\author{
Jens Kjærsgaard* \\ Institute of Food and Resource Economics, Rolighedsvej 25, 1958 Frederiksberg, Denmark
}

\section{A R T I C L E I N F O}

\section{Article history:}

Available online 28 December 2009

\section{JEL classification:}

C61

C67

D24

L52

Q22

Keywords:

Industry capacity

Data envelopment analysis

Multiple objective programming

Tradeoffs

\begin{abstract}
A B S T R A C T
The effective management of natural resources is a critical issue that concerns many people with differing interests. This paper examines aspects of overcapacity and optimal capacity within fisheries by accounting for multiple objectives. Overcapacity arises when a fishing fleet is capable of producing more than what is demanded at the industry level, or allowed by a regulatory framework. The presence of multiple objectives within fisheries management is most often an unavoidable reality, where the objectives determine what level of overcapacity is considered optimal. A two-stage model is suggested that can produce information for management in terms of tradeoffs, policy frontiers, objective values and optimal fleet structure. In the first stage, an output-based Data Envelopment Analysis (DEA) model is applied. Efficiency is evaluated and production units transformed such that they use technologically efficient inputs and produce at their full potential. In the second stage, these transformed units are included in an aggregate industry model formulated as a multi-objective optimization program. The model provides information for managers in terms of tradeoffs, policy frontiers, objective values, and optimal fleet structure (by generating Pareto optimal solutions). The proposed model has then been applied to the Danish commercial fishing fleet.
\end{abstract}

(c) 2009 Elsevier Ltd. All rights reserved.

\section{Introduction}

Overcapacity refers to the situation where an industry is capable of producing more than what is demanded at the industry level, or allowed by a regulatory framework. In fisheries, overcapacity occurs if there is an imbalance between fishing capacity and available resources. It is widely agreed that such a situation leads to biological overfishing and underutilization of capital assets. Reducing excess capacity, and, thereby, a lump of fixed costs, will generally see overall profits rise. Furthermore, recovery of the fish stocks would eventually improve the fishing potential going forward, and affect the balance between capacity and resources.

Industry capacity and production efficiency are well-studied subjects. Capacity can be measured in different ways, and the concept of optimal capacity is by no means uniquely defined. Traditionally, in fisheries, a distinction is made between input and output related measures. This may involve a vessel's physical characteristics, or its ability to catch fish [8,9]. In the economic literature, an output-based measure is generally applied $[9,25,26,31]$, and can be either technology- or economically-based.

In a purely technological sense, capacity is the maximum possible output that can be produced given full and efficient use of

\footnotetext{
* Tel.: +4545331708.

E-mail address: jenskj@privat.dk
}

variable inputs and existing technology. An economic-based definition of capacity is defined by the economically optimal (profitmaximizing or cost-minimizing) level of outputs.

The current research also takes an output-based approach, but adds another dimension to the analysis. In particular, we consider it essential to acknowledge the existence of potentially conflicting goals when analysing overcapacity issues in fisheries. As pointed out in [10] "the optimal level of capacity will depend on the objective of management." From a purely economic (profit-maximizing) perspective, overcapacity and underutilization of capital assets is undesirable since the capital could potentially generate a rent elsewhere in the economy. But, in a socio-economic optimum with multiple conflicting objectives, overcapacity may not be entirely unwanted. For example, maintaining employment levels in rural areas or ensuring sustainable production could be important. We thus suggest below that an optimal allocation of input factors may not correspond to a scenario without overcapacity. Keeping economic allocative optimality as a point of reference, tradeoffs between objectives may reveal the "cost" of achieving specified levels of various criteria ("objectives" and "criteria" are used synonymously).

In [21], Johansen considers capacity in terms of production capability and defines (short-run) capacity as "the maximum amount that can be produced per unit of time with existing plant and equipment, provided that the availability of variable factors of production is not restricted". This definition is adopted in the 
current analysis. Most fisheries are managed by periodicallyadjusted restrictions designed to limit total extractions from the resources to given levels. Industry capacity is evaluated relative to these levels. An output-based approach that accesses production capability and plant capacity utilization is thus considered appropriate.

Multiple Criteria Decision Making (MCDM), including MultiObjective Programming (MOP), allows the decision-maker to include various interests in the analysis. Furthermore, it forces him to explicitly state the possibly wide range of relevant objectives while recognizing that tradeoffs between objectives are usually an unavoidable reality (viz., increase in one objective may cause a decrease in another).

\subsection{Investigating optimal capacity}

The purpose of this article is to construct models wherein consequences from management initiatives can be evaluated and related to the production capacity constraints and multiple objectives relevant to the fishery industry. The proposed framework is then applied to the Danish commercial fishing fleet.

Optimal capacity and fleet adjustment are assessed in a broader perspective, simultaneously taking into consideration issues such as profit, employment, and bycatch (catch of non-target species). Decision variables in the model involve fleet structure and allocation of effort, as well as information on which vessels should be excluded. This can assist managers when vessel scrapping and buyback programmes are designed.

Overcapacity is the concern of managers/regulators which, in our case, includes the Danish Ministry of Food, Agriculture and Fisheries and the European Union (EU). In general, such entities seek to discourage the overexploitation of relevant resources. Fisheries are threatened by the tragedy of the commons since individual firms generally do not account for the fact that their (marginal) exploitation of critical resources affects future conditions of the stocks $[19,20]$. The proposed framework involves an industry management model that assesses overcapacity wherein the decision variables represent fleet structure (number of vessels within different fleet segments), and the allocation of effort (number of fishing days for the various vessels), i.e., the activity of different vessels in different areas.

We show how the model's objectives are traded off against each other, and that the optimal (most preferred) level of industry capacity helps reveal the underlying preferences of managers. The industry achieves near full capacity utilization when profit is maximized, meaning that overcapacity is close to fully undesired. Further, profit is negatively related to increasing employment. As the latter increases, capacity utilization decreases causing overcapacity to increase. Our analysis also indicates that capacity should be reduced in order to lower bycatch. The Danish commercial fishing fleet studied in the current article is overcapitalized and capable of catching up to approximately $50 \%$ more than allowed for various species (see Section 3.2).

Fisheries attract attention from numerous stakeholders, including regulators, fishermen, environmentalists, and labour unions. It is thus relevant, and natural, to consider multiple objectives in designing regulations that account for the inevitably different viewpoints involving management of the sector. While substantial effort has been made in developing bio-economic models, Mardle and Pascoe [30] point out that they may not be adopted by managers as they fail to incorporate multiple objectives. In general, then, single perspective guidelines should be avoided when modelling scenarios involving nature. With this in mind, we propose an MCDM model to better support those making decisions involving fishing capacity.
The model is composed of two components. First, an outputbased Data Envelopment Analysis (DEA) is applied [4]. Efficiency is evaluated and production units transformed, on an individual basis, such that they use technologically efficient inputs, and expand outputs as much as plant capacity allows. Hereafter, these transformed units with higher production capabilities are included in an aggregate industry model formulated as a multi-objective optimization program. An appealing feature of combining the two stages is that tradeoffs between problem objectives and optimal capacity can be evaluated on the production possibility frontier thus allowing vessels to produce at their full potential. In this regard, sector level analyses generally do not correct for individual inefficiencies.

DEA and MCDM are well established methodologies with the theory in both fields continuing to develop. It is thus interesting that the potential value of combining the two structures has not been well explored. Kerstens et al. [23], however, proposed a similar two-stage model with a DEA feeding input to a mathematical programming model for the Danish fishing industry. The objective involved minimizing fixed inputs to a fishing fleet with the industry program accounting for selected management initiatives via model constraints (see also [7,13,37] for analyses regarding the estimation of minimum input(s) required to maintain outputs for a given industry).

In [18], for example, a DEA model at the industry level was extended to evaluate tradeoffs between efficiency, effectiveness and equality by introducing effectiveness thresholds and equality constraints. Commensurability of outputs was assumed, and a "one-shot" DEA carried out. (Several examples of industry DEA models involving the Danish fishing fleet can be found in $[1,24,29]$ ).

Applications of MCDM to fisheries are reviewed in [28]. They are categorised as employing either multi-objective programming (MOP) or evaluation methods. The former involves determining the optimal allocation of assets given an array of objectives, whereas the latter typically deals with multiple criteria problems with a discrete and finite (small) number of alternative management actions. For present purposes, an MOP is applied. (See [33,34] for additional applications.) For more traditional, single-objective economic industry models, see [17] where numerical allocation approaches in European fisheries are surveyed. General introductions to multiple objective decision making can be found in $[36,39]$.

The current article is organised as follows. In Section 2, the proposed multi-criteria model for evaluating optimal production capacity is presented in a generalized form. The model is then applied to the Danish commercial fishing fleet in Section 3. The empirical analysis begins with a description of the data, followed by an analysis of the model's (industry') production potential. Thereafter, tradeoffs between management objectives and corresponding optimal allocations of fishing activities are identified. Section 4 concludes the paper with key implications of the analysis, including the potential for modelling various management scenarios using the suggested model.

\section{Proposed multi-objective model for evaluating optimal production capacities}

This section describes a general framework wherein optimal production capacity can be evaluated with respect to multiple objectives.

Consider $N$ production units and assume that total production is restricted. Assume, further, that the units produce in a technically efficient way (according to "best practice") and fully utilize their physical capital. Then, the question is: What is the optimal industry capacity and individual capacity utilization, given that the term "optimal" depends of an array of objectives?

As mentioned in the Introduction, the current analysis is conducted in two stages. In Stage 1, an output-based Data Envelopment 
Analysis (DEA) model is applied to evaluate total production capacity and appropriately transform production units, i.e., such that they use inputs technologically efficiently and expand outputs as much as possible (on an individual basis). The original study introducing the term DEA is that of Charnes, Cooper, and Rhodes (CCR) [3] in the late 1970s; but, the fundament for non-parametric measurement of production efficiency dates back to Farrell [16] in the 1950s. An introduction to the methodology, and selected applications, can be found in [4]. See, also, [14] for a thorough description of production frontiers. An earlier application of the approach used in Stage 1 is found in [22], and deals with the technical efficiency and capacity utilization for hospitals.

In Stage 2, the transformed units are included in an industry multi-objective optimization program. The proposed structure determines the optimal allocation of fleet effort and capacity, and, for each unit, the degree of potential activity. Objectives and their tradeoffs can be evaluated, as well as the capacity indicators.

\subsection{Stage 1} let:

Assume there are $N$ production units, $I$ inputs, and $J$ outputs, and

$n=1, \ldots, N \quad$ : Production units

$x_{k i}: i=1, \ldots, I, k=1, \ldots, N \quad:$ Input $i$ forunit $k$

$y_{k j}: j=1, \ldots, J, k=1, \ldots, N \quad:$ Output $j$ for unit $k$

Let $(x, y)$ be an $I+J$ dimensional vector of inputs and outputs. The production possibility set, or technology $Y$, is defined as follows:

$Y=\left\{(x, y) \in \Re^{I+J} \mid x\right.$ can produce $\left.y\right\}$

In DEA, an inner approximation of the true technology $Y$ is based on empirical data such that the actual observations are enveloped by the production possibility set according to a minimal series of assumptions. The empirical technology is then described by:

$Y^{e}=\left\{(x, y) \in \Re^{I+J} \mid \sum_{n=1}^{N} \lambda_{n} x_{n} \leq x, \sum_{n=1}^{N} \lambda_{n} y_{n} \geq y, \lambda \in \Lambda\right\}$,

where $\lambda$ is a vector of weights indicating the observations to which $(x, y)$ is compared, and $\Lambda$ specifies an assumption about returns to scale of the technology, i.e. $\Lambda^{\text {crs }}=\Re_{+}^{N}$ describes constant returns to scale (CRS), $\Lambda^{\text {nirs }}=\left\{\lambda \in \Re_{+}^{N} \mid \sum_{n=1}^{N} \lambda_{n} \leq 1\right\}$ non-increasing returns to scale (NIRS), and $\Lambda^{\mathrm{vrs}}=\left\{\lambda \in \Re_{+}^{N} \mid \sum_{n=1}^{N} \lambda_{n}=1\right\}$ variable returns to scale (VRS).

CRS refers to a situation where radial expansion or contraction of observations is allowed. NIRS allows combinations of observations, but not (unbounded) expansion. And, VRS corresponds to NIRS, but observations cannot be radially contracted to the origin. In addition, the empirical technology has properties of free disposal and convexity.

In output-based DEA, the efficiency measure $\theta$ describes by how much outputs can be proportionally expanded (i.e., with the output mix kept unchanged), given the observed use of inputs. For unit $k$, the output oriented efficiency measure $\theta$ can be computed as:

$\theta_{k}^{*}=\max \left\{\theta \mid\left(x_{k}, \theta y_{k}\right) \in Y^{e}\right\}$.

The above efficiency measure describes how much production unit $k$ can increase all its outputs (fixed output mix) given technology $Y^{e}$, and with its current use of inputs. When $\theta_{k}^{*}=1$, the implication is that unit $k$ is efficient (on the efficient frontier), whereas $\theta_{k}^{*}>1$ means that unit $k$ is technologically inefficient. Note that unit $k$ is, via the empirical technology, measured relative to an empirical frontier spanned by the other observations. The empirical technology is thus an inner approximation of the true technology, since best practice is not guaranteed to be efficient, i.e., the efficiency appraisal provides but a relative measure. Furthermore, the measure is influenced by the producers' operating environment, e.g., through regulation.

In accordance with the Johansen capacity measure [21], a distinction is made between fixed and variable inputs. Furthermore, it is assumed that there are no restrictions on variable inputs. In this way, total production capacity is captured, while accounting for both technically efficient input use and full utilization of physical capital. A technology with variable returns to scale is adopted. This is a common short term assumption and seems in reasonable agreement with the fact that some inputs are considered fixed.

Let $I_{\mathrm{f}}$ and $I_{\mathrm{V}}$ be two sets that define a partition between the fixed and variable inputs. Given that there are no restrictions on variable inputs, the production possibility set of the empirical technology then becomes:

$\bar{Y}^{e}=\left\{(x, y) \in \Re^{I+J} \mid \sum_{n=1}^{N} \lambda_{n} x_{n i} \leq x_{i}, i \in I_{f}, \sum_{n=1}^{N} \lambda_{n} y_{n} \geq y, \lambda \in \Lambda\right\}$.

For individual production unit $k$, the program for the multi-output efficiency measure becomes (based on [11], and assuming VRS):

$\operatorname{Max}_{k}$
s.t.
$\sum_{n=1}^{N} \lambda_{n} y_{n j} \geq \theta_{k} y_{k j}, \quad j=1, \ldots, J$
$\sum_{n=1}^{N} \lambda_{n} x_{n i} \leq x_{k i}, \quad i \in I_{f}$
$\sum_{n=1}^{N} \lambda_{n}=1, \lambda_{n} \geq 0, \quad n=1, \ldots, N$.

The program is solved for all units, $k=1, . ., N$, providing a vector $\left(\theta_{1}^{*}, \ldots, \theta_{N}^{*}\right)$ of the efficiency measures and the matrix $\left(\lambda_{n k}^{*}\right)_{n, k=1, \ldots N}$ for the sample of interest.Uncorrected capacity utilization of production unit $k$ can then be stated as:

$C U_{k}=\frac{1}{\theta_{k}^{*}}, \quad k=1, \ldots, N$.

Let $\bar{\theta}_{k}$ be the solution if the variable inputs were not allowed to change; that is, if restrictions were imposed on the variable inputs in program (5), corresponding to technology (2). Then, the corrected capacity utilization of production unit $k$ is given by:

$C C U_{k}=\frac{\bar{\theta}_{k}}{\theta_{k}^{*}}, k=1, \ldots, N$.

The distinction between uncorrected and corrected capacity utilization is based on [12]. It captures the idea that the possible expansion of production can be decomposed in terms of technical inefficiency and underutilization of capital assets.

Equations (8) and (9) below are modest attempts to obtain a measure of total industry overcapacity. In other words, based on the DEA, how much is the industry capable of catching relative to what is demanded, or allowed, by a regulatory framework (quotas)? Aggregation is a well-known challenge within economics. The presence of multiple outputs complicates matters further. Aggregation of individual efficiency measures to obtain an estimate of industry efficiency is not pursued here (see [2] or [15]). On the other hand, a first estimate for industry overcapacity could be calculated as total production capacity (all outputs) divided by 
the sum of maximal allowable productions, $y_{j}^{\max }(j=1, \ldots, J)$, assuming that the different outputs are units-commensurable so that aggregation is feasible and meaningful, i.e.:

OC $=\frac{\sum_{j=1}^{J} \sum_{n=1}^{N} \theta_{n}^{*} y_{n j}}{\sum_{j=1}^{J} y_{j}^{\max }}$.

In reality, however, crude aggregation of the different outputs may not be appropriate. Another, perhaps more reasonable, approach is to evaluate overcapacity for each output, as done in [38]:

$O C_{j}=\frac{\sum_{n=1}^{N} \theta_{n j}^{*} y_{n j}}{y_{j}^{\max }}$.

In the second stage of our analysis, production units are assumed capable of operating technologically efficient, and at full capacity. Hence, the observations are transformed as follows:

Assign : $\left\{\begin{array}{l}x_{k i}:=\sum_{n=1}^{N} \lambda_{n k}^{*} x_{n i}, i \in I_{v}, k=1, \ldots, N \\ y_{k j}:=\theta_{k}^{*} y_{k j}, j=1, . ., J, k=1, \ldots, N .\end{array}\right.$,

Fixed inputs remain unchanged. This is in agreement with the short-run perspective of the present analysis. The two equations in expression (10) state that production unit $k$ (for all $k$ ) is projected onto the frontier. However, there may be positive slacks for the outputs. The scalar expansion is applied for two reasons. Firstly, it ensures an unchanged output mix. Secondly, our application to the Danish fishing fleet, i.e. the industry model of Stage 2, has a higher level of detail where outputs are not grouped as is the case in Stage 1. (The scalars are calculated based on output groups, but can applied to individual outputs in Stage 2.)

\subsection{Stage 2}

Structuring a management scenario as a Multiple Criteria Decision Making (MCDM) problem allows for the inclusion of different, and even diverging, opinions about management goals via a vector of objectives. Tradeoffs can be evaluated, where the "best" solution depends on all objectives simultaneously. The underpinning principle in MCDM is Pareto optimality rather than (unique) optimality; but, it is possible to incorporate preferences towards the objectives, which will then reveal an (subjective) optimal solution.

MCDM covers a wide range of techniques. As previously mentioned, approaches can be considered as being within either of the following two categories: 1) Multi-Objective Programming (MOP) or 2) Evaluation (Multi-Criteria Decision Analysis) methods. The former is generally used to determine the optimal allocation of assets given an array of objectives. The latter typically deals with multiple criteria problems where there is a discrete and finite (small) number of alternative management actions. The model framework developed here fits within the first category.

The MOP analysis is based on the results from Stage 1. Given the transformation in equation (10), all units are capable of producing at full potential capacity.

Consider $M$ objectives, $m=1, \ldots, M$, and let $O_{k}=\left(O_{k}^{1}, \ldots, O_{k}^{M}\right)$ be the properties of unit $k$ with respect to the $M$ objectives. Furthermore, define the vector $z \in S$, where $S$ is the $n$-dimensional unit simplex, i.e., $0 \leq z_{k} \leq 1, \forall k \in\{1, \ldots, N\}$.

Assume there are $L$ constraints, and the properties of unit $k$ $(1 \leq k \leq N)$ with respect to the constraints are $\mathbf{P}_{k}=\left(P_{k}^{1}, \ldots, P_{k}^{L}\right)$.

The multi-objective optimization program then takes the form:

$$
\begin{aligned}
& \operatorname{Max} \sum_{n=1}^{N} z_{n} O_{n}^{1} \\
& \quad \vdots \\
& \operatorname{Max} \sum_{n=1}^{N} z_{n} O_{n}^{M} \\
& \text { s.t. } \\
& \sum_{n=1}^{N} z_{n} P_{n}^{1} \leq C^{1} \\
& \vdots \\
& \sum_{n=1}^{N} z_{n} P_{n}^{L} \leq C^{L} \\
& 0 \leq z_{n} \leq 1, C=\left(C^{1}, \ldots, C^{L}\right) \in \Re^{L}, \quad n=1, \ldots, N .
\end{aligned}
$$

A solution vector $z^{*} \in S$ is generated, specifying the (optimal) degree of activity for each production unit. The relationships to Stage 1 are incorporated in the vectors $O_{k}, P_{k}, k=1, \ldots, N$ and $C$. When a specific problem is considered, additional/relevant endogenous variables and constraints may be introduced as in the application, below, to the Danish fishing fleet (see Section 3).

There are three main approaches to solving (11): (i) Weighted sum (or Archimedean) optimization, (ii) lexicographic (or preemptive) optimization, and iii) generating techniques. The approaches are briefly discussed in turn.

First, in the weighted sum approach, a single aggregated objective is formed as the weighted sum of the objectives, and the sum is then maximized. Although this formulation is intuitively appealing, the modeller must account for objectives measured in both varying units and values. Moreover, meaningful weights are essential. This implies that there is some risk that the results are biased if proper scaling is not applied. Moreover, the modeller requires explicit weights to aggregate the objectives. The resulting model's outcomes are thus subject to these weights.

Second, a lexicographic ordering places objectives at different levels based on their importance to the decision-maker. This approach is appropriate if some objectives are infinitely more important (pre-emptive) than others. Objectives on the same level can be aggregated as a weighted sum.

Third, and finally, generating techniques produce a series of non-dominated solutions and do not involve a predetermined set of weights. They actually generate Pareto optimal solutions, i.e. there is no alternative solution that improves one objective without worsening at least one other.

The following case-study focuses on the generation of nondominated solutions since the purpose of the analysis is to show how the optimal (most preferred) level of industry capacity depends on the underlying preferences of managers, implying that objectives are traded off against one another as well as the degree of overcapacity.

The $\varepsilon$-constraint method is applied to produce a series of nondominated solutions to the program in (11). One objective is optimized at a time and a vector $\varepsilon$ defines minimum requirement levels for all other objectives. This eliminates some of the feasible solutions, which is why the approach is sometimes referred to as the 'reduced feasible region method.' Solutions are generated by parametric variation of $\varepsilon$ and by switching objectives. If the solution to this program is unique, then it is also non-dominated (see [36]). This approach does not rely on an a priori determination of management weights. However, the generated solutions can help managers assess tradeoffs and identify a most preferred combined achievement of objectives, in which case the underlying management preferences (weightings) are exposed. This holds since every combination of objectives can be achieved by maximizing some weighted sum of the objectives ([36, Theorem 9.6]). If the management weights were known and explicitly stated, it would 
Table 1

Data dimensions.

\begin{tabular}{ll}
\hline Fleet segment: & 26 alternatives \\
County: & 14 alternatives \\
Fishing area: & 30 alternatives \\
Species: & 93 alternatives \\
\hline
\end{tabular}

be straightforward to include them in the model so as to achieve the corresponding optimal solution.

Stage 2 provides information on the level overcapacity as a function of achievement across the various objectives. The Stage 1 transformation ensures that the tradeoffs are evaluated on the technologically efficient frontier.

\section{Management of the Danish fishing fleet}

A previous study on multi-objective management of the Danish industrial fishery (for reduction) in the North Sea revealed the presence of a range of stakeholders and objectives. Researchers from the Institute for Fisheries Management and Coastal

Table 2

Vessels included for year 2003.

\begin{tabular}{|c|c|c|c|c|c|}
\hline Length & Segment & $\begin{array}{l}\text { Number } \\
\text { of vessels }\end{array}$ & $\begin{array}{l}\text { Gross } \\
\text { tonnage } \\
(\mathrm{GT})\end{array}$ & $\begin{array}{l}\text { Horse } \\
\text { Power } \\
(\mathrm{HP})\end{array}$ & $\begin{array}{l}\text { Catch value } \\
\text { relative to } \\
\text { total }\end{array}$ \\
\hline \multirow[t]{4}{*}{$<12 \mathrm{~m}$} & $\begin{array}{l}\text { Liners and gill } \\
\text { netters }\end{array}$ & 79 & 698 & 8849 & $2 \%$ \\
\hline & Trap setters etc. & 7 & 63 & 643 & $0 \%$ \\
\hline & $\begin{array}{l}\text { Danish seiners/ } \\
\text { netters/trawlers }\end{array}$ & 26 & 314 & 3605 & $1 \%$ \\
\hline & Trawlers & 21 & 293 & 3416 & $0 \%$ \\
\hline Total & & 133 & 1368 & 16,513 & $3 \%$ \\
\hline \multirow[t]{4}{*}{$12-15 \mathrm{~m}$} & $\begin{array}{l}\text { Liners and gill } \\
\text { netters }\end{array}$ & 61 & 1116 & 9890 & $3 \%$ \\
\hline & $\begin{array}{l}\text { Danish seiners/ } \\
\text { netters/trawlers }\end{array}$ & 33 & 578 & 6080 & $1 \%$ \\
\hline & Danish seiners & 15 & 288 & 2677 & $1 \%$ \\
\hline & Trawlers & 130 & 2902 & 29,012 & $5 \%$ \\
\hline Total & & 239 & 4883 & 47,659 & $10 \%$ \\
\hline \multirow[t]{4}{*}{$15-18 \mathrm{~m}$} & $\begin{array}{l}\text { Liners and gill } \\
\text { netters }\end{array}$ & 34 & 1359 & 7920 & $3 \%$ \\
\hline & $\begin{array}{l}\text { Danish seiners/ } \\
\text { netters/trawlers }\end{array}$ & 7 & 205 & 1550 & $0 \%$ \\
\hline & Danish seiners & 20 & 687 & 3876 & $1 \%$ \\
\hline & Trawlers & 105 & 3704 & 30,915 & $7 \%$ \\
\hline Total & & 166 & 5954 & 44,261 & $12 \%$ \\
\hline \multirow[t]{4}{*}{$18-24 \mathrm{~m}$} & $\begin{array}{l}\text { Liners and gill } \\
\text { netters }\end{array}$ & 20 & 1701 & 6606 & $2 \%$ \\
\hline & $\begin{array}{l}\text { Danish seiners/ } \\
\text { netters/trawlers }\end{array}$ & 7 & 910 & 3685 & $1 \%$ \\
\hline & Danish seiners & 33 & 2096 & 9126 & $3 \%$ \\
\hline & Trawlers & 106 & 8983 & 47,945 & $12 \%$ \\
\hline Total & & 166 & 13,691 & 67,362 & $18 \%$ \\
\hline \multirow[t]{5}{*}{$24-40 \mathrm{~m}$} & Beam trawlers & 8 & 2348 & 9604 & $3 \%$ \\
\hline & $\begin{array}{l}\text { Danish seiners/ } \\
\text { netters/trawlers }\end{array}$ & 5 & 1244 & 3505 & $1 \%$ \\
\hline & Trawlers, mixed & 26 & 7273 & 23,931 & $5 \%$ \\
\hline & $\begin{array}{l}\text { Trawlers, } \\
\text { industrial }\end{array}$ & 45 & 13,024 & 36,110 & $9 \%$ \\
\hline & $\begin{array}{l}\text { Trawlers, } \\
\text { consumption }\end{array}$ & 53 & 10,728 & 40,973 & $11 \%$ \\
\hline Total & & 137 & 34,617 & 114,123 & $29 \%$ \\
\hline \multirow[t]{3}{*}{$>40 \mathrm{~m}$} & Purse seiners & 9 & 8050 & 22,423 & $9 \%$ \\
\hline & Trawlers, mixed & 19 & 9667 & 23,407 & $7 \%$ \\
\hline & $\begin{array}{l}\text { Trawlers, } \\
\text { industrial }\end{array}$ & 12 & 6216 & 15,278 & $4 \%$ \\
\hline \multicolumn{2}{|l|}{ Total } & 40 & 23,933 & 61,108 & $21 \%$ \\
\hline \multirow{2}{*}{$\begin{array}{r}\text { Specialized } \\
\text { fisheries }\end{array}$} & Northern prawn & 25 & 1125 & 6312 & $2 \%$ \\
\hline & Mussels & 62 & 1153 & 10,482 & $5 \%$ \\
\hline \multicolumn{2}{|c|}{ Total } & 87 & 2278 & 16,794 & $7 \%$ \\
\hline \multicolumn{2}{|c|}{ Total (All segments) } & 968 & 86,724 & 367,820 & $100 \%$ \\
\hline
\end{tabular}

Table 3

Model inputs and outputs.

$\begin{array}{ll}\text { Fixed inputs: } & \text { Gross tonnage (GT), Horse power (HP) } \\ \text { Variable inputs: } & \text { Labour, Days at sea } \\ \text { Outputs: } & \text { Cod, Other codfish, Mackerel, Herring, Shrimp and Norway } \\ & \text { Lobster, Industrial species, Other species, Plaice, Other } \\ & \text { flatfish, Northern prawn, Mussels }\end{array}$

Community Development identified such stakeholders and applied a pairwise comparison method based on Saaty's scale [35] to elicit stakeholders' preferences towards the various objectives [32]. This information was subsequently incorporated into a multi-objective (goal programming) program, and selected perspectives on optimal management analysed in [27]. The following objectives from this earlier work were adopted for the present analysis.

\section{1) Maximize Profit/Revenue \\ 2) Maximize Employment \\ 3) Minimize Bycatch.}

These objectives are general in the sense that they apply to most commercial fisheries; in particular, here, to Danish fisheries. (Remaining objectives in [32] primarily represent interests specific to Danish industrial fishery for sand-eel and Norway pout in the North Sea.)

Utilization of fixed capital (relative to potential) was evaluated for the different solutions. (It could also be included as one of the study objectives.) The intuitively reasonable result, that this measure is closely related to the profit objective, was confirmed by our analysis, discussed below. Other relevant objectives that could be taken into consideration include concerns about the ecosystem, as well as breeding grounds for birds and marine mammals, and/or marine-protected areas. The ability to incorporate such objectives into our proposed model depends, of course, on available data. For example, how do the various gear types (vessel segments) interfere with the ecosystem.

\subsection{Data and conditioning}

The two primary data sources for the current study are: 1) Databases prepared and maintained by The Danish Fisheries Directorate (FD), and 2) Account statistics prepared by the statistical department at the Food and Resource Economic Institute (FOI). In addition, the Danish quotas are attained from FD.

The databases from FD provided detailed information on individual catch and effort, as well as on vessel characteristics. Catch and effort were available with respect to species and area, while vessel characteristics include variables such as primary use of gear, tonnage, length, horse power, and number of crew members. Account statistics from FOI provided information on costs. Eight different cost categories were considered for the various fleet segments. Data from the year 2003 were applied.

The dimensions of data are shown in Table 1, below. Vessels were divided into 26 segments depending on length and use of gear. Furthermore, the segmentation separates vessels that participate in a specialized (licensed) fishery with limited entry (mussel, common shrimp and northern prawn fisheries). The county tells from what part of the country the vessels originate. Quota regulation operates within several so-called management areas. These, in general, are places that contain combinations of species and fishing areas. In total, the model includes 30 management areas covering the traditional locations for both non-quota and quota species. Most Danish vessels conduct a multi-species fishery. The breakdown of species is very detailed with a total of 93 species considered (includes both quota and non-quota restricted). 
Table 4

Efficiency, $\theta$, with uncorrected (CU) and corrected capacity utilization (CCU).

\begin{tabular}{|c|c|c|c|c|c|c|c|}
\hline & Number of vessels & Maximal $\theta$ & Average $\theta$ & Median $\theta$ & $95 \%$ of $\theta$ are below: & Average CU (\%) & Average CCU (\%) \\
\hline$<12 \mathrm{~m}$ & 133 & 7.81 & 2.05 & 1.63 & 4.47 & 63 & 86 \\
\hline $12-15 \mathrm{~m}$ & 239 & 7.83 & 1.98 & 1.64 & 4.20 & 62 & 77 \\
\hline $15-18 \mathrm{~m}$ & 166 & 6.91 & 1.56 & 1.26 & 3.11 & 76 & 91 \\
\hline $18-24 \mathrm{~m}$ & 166 & 10.21 & 1.57 & 1.28 & 3.01 & 76 & 89 \\
\hline $24-40 \mathrm{~m}$ & 137 & 13.57 & 1.50 & 1.33 & 2.34 & 78 & 94 \\
\hline$>40 \mathrm{~m}$ & 40 & 1.67 & 1.13 & 1.00 & 1.53 & 91 & 95 \\
\hline Specialized fisheries & 87 & 59.30 & 2.16 & 1.30 & 2.60 & 74 & 89 \\
\hline Total & 968 & 59.30 & 1.76 & 1.37 & 3.57 & 71 & 87 \\
\hline
\end{tabular}

The proposed model covers the entire commercial fishery sector in Denmark, i.e., vessels with minimum yearly revenue above a given threshold (approximately $€ 31,000$ in year 2003). ${ }^{1}$ It was assumed that the share of the fishery accounted for by noncommercial vessels remain constant over time.,

Table 2 shows the structure of the included vessels. The diversity of the fleet is apparent. Of 968 total vessels, the dominant share were small- or medium-sized (under $24 \mathrm{~m}$ ), that participated primarily in mixed fisheries for consumption species. Larger vessels, in excess of $24 \mathrm{~m}$, are more oriented towards industrial species (for reduction), herring and mackerel. Notice that the nine purse seiners over $40 \mathrm{~m}$ accounted for approximately $9 \%$ of catch value in 2003. Vessels more than $24 \mathrm{~m}$ accounted for $50 \%$ of catch value and $68 \%$ of gross tonnage. There were 87 vessels in licensed fishery for mussels and northern prawn. Common shrimp fishers were excluded since no cost data were available.

\subsection{Stage 1: DEA analysis - empirical results}

Table 3 lists the inputs and outputs used in the analysis. Fixed inputs include horse power (HP) and gross tonnage (GT) with variable inputs of labour and days at sea. In the short term, it is reasonable to consider GT and HP as fixed, whereas labour and days at sea can be adapted to given circumstances on short notice. The outputs include 11 homogenous groups of species, which provide a meaningful representation of Danish fisheries in terms of the main target species.

The Danish fleet as a whole is not a homogenous group (vessels participate in quite different fisheries) and are therefore not necessarily comparable in terms of technological use of inputs. Hence, not all vessels should be compared at the same time. In order to determine how calculations should be segmented, two alternatives were considered: 1) Distinguish between those vessels using different kinds of gear and belonging to different length groups (viz., the 26 fleet segments in Table 2), and 2) only distinguish between different length groups and specialized fisheries (i.e. seven groups, vessels aggregated within the six length categories and the specialized fisheries, see Table 2). In other words, under alternative (1), only vessels that use the same gear structure, and belong to the same length group are compared, whereas under alternative (2), only vessel length determines which vessels are compared.

Not surprisingly, the two above-mentioned alternative approaches have both advantages and disadvantages. On the one hand, it seems more appropriate to only compare vessels using the same type of gear. At the same time, the smaller the groups become, the higher is the tendency for the vessels to appear efficient (and therefore not capable of increasing output). That is to say, efficiency

\footnotetext{
1 The exchange rate in July 2005: 7.45 DKK $=1.21$ USD $=1$ EURO.

2 In 2003, commercial vessels accounted for more than $95 \%$ of the total value of landings.

${ }^{3}$ Vessels participating in the Greenland shrimp fishery were excluded.
}

estimates in small groups are downwards biased. Cooper et. al's rule of thumb [6, p. 252] suggests that there are at least $\max \{I \cdot J, 3$ $(I+J)\}$ observations in each group. Based on these considerations, the second alternative/case is used going forward.

Table 4, below, provides a summary of the resulting efficiency measures realized from the (seven) DEA analyses.

Note that the average efficiency measures tend to be larger for smaller vessels, which corresponds to a smaller degree of capacity utilization. Vessels over $40 \mathrm{~m}$ appear most efficient, which corresponds to higher capacity utilization. The efficiency measures (expansion factors) appear to be reliable, which is further supported by the observed median values and 95 percentiles. When the maximal efficiency measures are considered, the specialized fisheries separate from the group. The " 59.30 " derives from a vessel catching only a small amount of mussels, which does not negatively affect the subsequent analysis.

Average uncorrected capacity utilization (CU) varies from $62 \%$ for smaller vessels between 12 and $15 \mathrm{~m}-91 \%$ for vessels larger than $40 \mathrm{~m}$. The overall average is $71 \%$ suggesting that any commercial vessel in the Danish fishing fleet produces less than $3 / 4$ of its potential. The average corrected capacity utilization (CCU) appears approximately half way between CU and full capacity utilization (100\%). This implies that approximately half the possible increase in production could be achieved with the same level of inputs, if vessels were operating technologically efficiently.

When vessels are transformed in accordance with (10), i.e., operating at full capacity, then overcapacity can be evaluated for each output using (9). The results of this analysis are given in Table 5. (Recall that current overcapacity measures up to approximately $50 \%$ (53\% for shimp and Norway lobster).

The Table 5 results clearly indicate that there is an imbalance between available resources and fleet capacity. In eight of the 11 output groups, overcapacity exceeds $25 \%$. An interesting observation is that, in 2003, only herring was under individual transferable quotas (ITQ) regulation.

\subsection{Stage 2: Multi-objective programming (MOP) analysis - empirical results}

\subsubsection{Programming model}

Profit is defined as aggregated contribution margin (CM) less a minimum required rent (Minrent). Using average fleet segment fixed costs on individual vessels level instead of Minrent would have inappropriate consequences to the outcome by eliminating

Table 5

Overcapacity with respect to the output groups studied.

\begin{tabular}{lrll}
\hline Cod & $45 \%$ & Plaice & $37 \%$ \\
Other codfish & $28 \%$ & Other flatfish & $38 \%$ \\
Mackerel & $8 \%$ & Northern prawn & $32 \%$ \\
Herring & $12 \%$ & Mussels & $44 \%$ \\
Shrimp and Norway lobster & $53 \%$ & Other species & $20 \%$ \\
Industrial species & $30 \%$ & & \\
\hline
\end{tabular}


Table 6

Number of vessels, employees and share of revenue when either profit or employment is maximized.

\begin{tabular}{|c|c|c|c|c|c|c|c|c|}
\hline \multirow[t]{2}{*}{ Vessel length } & \multicolumn{3}{|l|}{ Number of vessels } & \multicolumn{3}{|l|}{ Number of employees } & \multicolumn{2}{|l|}{ Share of revenue (\%) } \\
\hline & Max. Employ. (Basis) & Max. Profit & $\Delta(\%)$ & Max. Employ. (Basis) & Max. Profit & $\Delta(\%)$ & Max. Employ. (Basis) & Max. Profit \\
\hline$<12 \mathrm{~m}$ & 133 & 58 & -56 & 168 & 78 & -54 & 3 & 1 \\
\hline $12-15 \mathrm{~m}$ & 239 & 103 & -57 & 553 & 252 & -55 & 10 & 5 \\
\hline $15-18 \mathrm{~m}$ & 166 & 130 & -22 & 405 & 328 & -19 & 12 & 11 \\
\hline $18-24 \mathrm{~m}$ & 166 & 88 & -47 & 517 & 290 & -44 & 18 & 13 \\
\hline $24-40 \mathrm{~m}$ & 137 & 100 & -27 & 574 & 452 & -21 & 29 & 33 \\
\hline$>40 \mathrm{~m}$ & 40 & 23 & -43 & 273 & 188 & -31 & 21 & 26 \\
\hline Specialized & 87 & 60 & -31 & 156 & 106 & -32 & 7 & 11 \\
\hline Total & 968 & 562 & -42 & 2646 & 1694 & -36 & 100 & 100 \\
\hline
\end{tabular}

Note: $\Delta$ refers to the relative change.

many vessels from the analysis, which is not realistic. Employment is defined here as the aggregated number of crew members for active vessels, while bycatch is the sum of bycatch indices related to the individual vessels (based on the value of non-target landings). This is a particularly simplified measure of bycatch and only serves the present analysis by way of example. Bycatch is reduced by allocating less activity to vessels with large bycatch indices. This approach has the effect of imposing weak disposability, as it is modeled in [5]. Reductions of undesired outputs are only possible if desired outputs are reduced in the same proportion.

The proposed program is outlined as (12):

$\operatorname{Max} \sum_{n}\left(z_{n} C M_{n}-b_{n}\right.$ Minrent $\left._{n}\right) \quad$ (Profit)

$\operatorname{Max} \sum_{n} b_{n}$ Crew Members $n$ (Employment)

$\operatorname{Min} \sum_{n} z_{n}$ Bycatch $_{n} \quad$ (Bycatch)

s.t.

$\sum_{n} z_{n} y_{n j a} \leq T A C_{j a}, \forall j, a \quad$ (Quota restriction)

$z_{n}$ REVENUE $_{n} \geq \alpha b_{n}$ REVENUE $_{n}^{2003}, \forall n$ (Minimum CM if active)

$0 \leq z_{n} \leq 1, b_{n} \in\{0,1\}, z_{n} \leq b_{n}, \forall n$,

where $z_{n}$ is the degree of activity for vessel $n$, and $b_{n}$ is a binary variable representing whether or not vessel $n$ is active.

Contribution margin equals revenue less variable operating costs, sales costs and crew payment. Minrent ${ }_{n}$ is a percentage of insurance value for vessel $n$, which is used to approximate fixed cost via invested capital. The number of crew members on vessel $n$ is Crew Members $n$. Bycatch ${ }_{n}$ is an index for vessel $n$, representing the share of catch value that comes from non-target species. The potential catch of species $j$ in area $a$ by vessel $n$ is given by $y_{n j a}$, while the total allowable catch of species $j$ in area $a$ is represented by $T A C_{j a}$. Finally, $R E V E N U E_{n}$ describes the potential revenue for

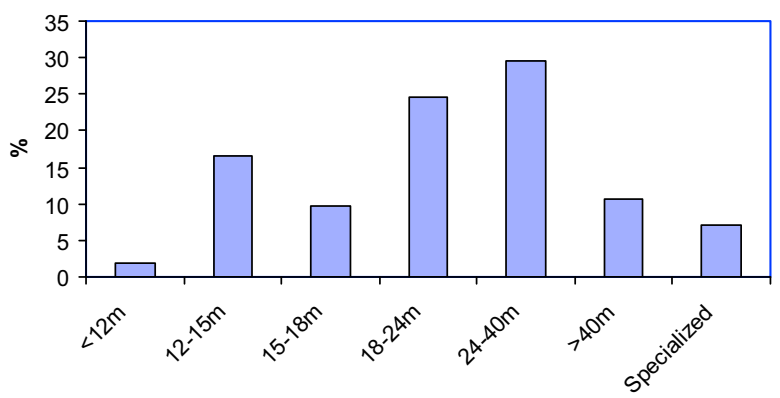

Fig. 1. Distribution of reduction (approximated) in fishing capacity when profit is maximized. vessel $n$ while $\operatorname{REVENUE}_{n}^{2003}$ is the actual revenue for vessel $n$ in 2003. It is assumed that vessels only remain active if their revenue is at least $\alpha$ ( 0.5 is applied hereafter) times 2003 revenue.

The program returns two vectors, $z$ and $b$, where $0 \leq z \leq 1$ describes the degree of activity for each of the 968 commercial vessels, and $\boldsymbol{b}$ is a binary vector, with an entry equal to 1 for a vessel which is active (i.e. corresponding entry in $z$ is strictly positive), and 0 otherwise. If a vessel is active (no matter the degree of activity), the binary variable induces a fixed cost. The solution thus provides a composition of the fleet, and corresponding individual activity levels. If $b_{n}=1$, for all $n$, then all original vessels are included.

The three objectives in program (12) are formulated as aggregated measures for the Danish commercial fleet as a whole. However, this need not be the case. The model is able to distinguish between, for example, different management areas, species, and/or home regions of the vessels. In other words, the model allows for other, and perhaps more sophisticated, (re)formulations of the objectives.

To track utilization of fixed capital, the averages of the individual utilization rates corresponding to the different MOP solutions are calculated. It is here described as the average degree of activity (relative to the potential) for all active vessels. The measure, $P$, is defined as:

$P=\frac{\sum_{n} z_{n}}{\sum_{n} b_{n}} . \quad$ Average utilization of fixed capital

\subsubsection{Comparison of single-criteria optimal solutions}

Initially, only two criteria are considered, profit and employment. Employment is maximal if all vessels remain active, corresponding to the actual Danish commercial fleet in 2003, i.e. this is the basis (and employment maximizing) scenario. As a point of reference a single-objective optimization of profit has been

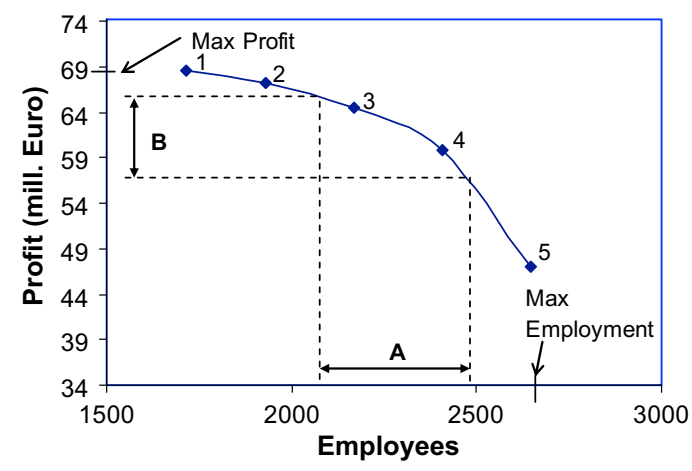

Fig. 2. Tradeoff between profit and employment. 


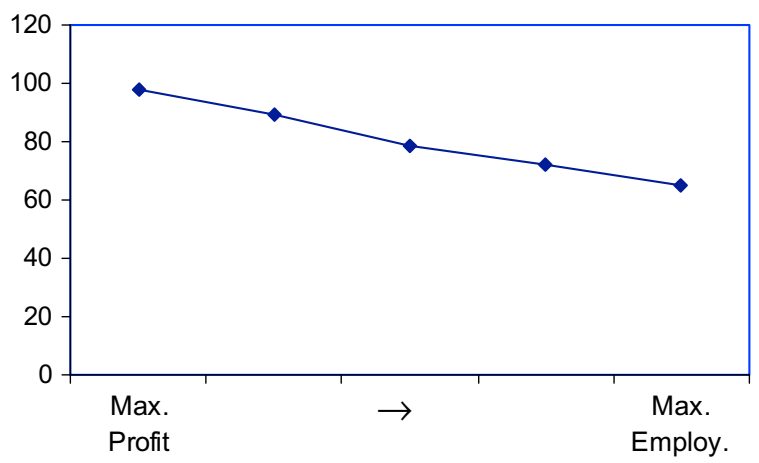

Fig. 3. Tradeoff in use of fixed capital $-P(\%)$.

conducted. The results of the two extremes with respect to allocation of vessels and employees are given in Table 6.

In terms of both numbers of vessels and employees, the profit maximizing scenario suggests large reductions relative to the basis scenario. In total, $42 \%$ of the vessels and $36 \%$ of the employees would be expected to leave the fishery when profit is maximized. This suggests that, from a profit maximizing perspective, there is severe overcapacity. The largest relative reduction is suggested for vessels under $15 \mathrm{~m}$; but the numbers of larger vessels, which are dominant in catch quantities, should also be significantly reduced.

The last two columns of Table 6 show how revenue is allocated between the different vessel length groups. In particular, it describes $s$ how revenue is concentrated on larger vessels when profit is maximized. In other words, maximizing profit and reducing overcapacity results in relatively greater use of larger vessels. Such ships are less labour intensive (revenue (and profit) per employee is smaller). This, in turn, suggests that the marginal loss in profit from including an employee diminishes as vessels, in particular smaller vessels, are excluded. However, the profit maximizing solution relies mostly on reducing capacity within the larger groups, i.e., in order to maximize profit, more capacity in terms of catching capability has to be taken out of the larger length groups. This phenomenon is displayed in Fig. 1. Note that the reduction in number of vessels is weighted by the profit maximizing distribution of revenue (Table 6) in order to achieve a measure of reduction in fishing capacity across all length groups.

\subsubsection{Tradeoff between profit and employment}

Fig. 2 shows the tradeoff-curve between profit and employment achieved by applying the $\varepsilon$-constraint method. It appears clearly that profit decreases with increasing employment, and that there was excess employment and capital tied up in the fishery. In other words, a more effective economic utilization of the production units was possible at the expense of employment.

Importantly, the curve can be used to clarify and quantify tradeoffs in management objectives. For example, are we willing to reduce employment by A to achieve an increase of B in profit? Or, what is the marginal loss in profit from employing one additional fisherman? The slopes of the piecewise linear curve connecting the points in Fig. 2 (see Table 7) can be used to address the latter question.

\section{Table 7}

Slopes of piecewise linear curve in Fig. 2 (Euros).

\begin{tabular}{lr}
\hline Slope $1-2$ & -4630 \\
Slope $2-3$ & -12605 \\
Slope $3-4$ & -21008 \\
Slope $4-5$ & -54393 \\
\hline
\end{tabular}

Table 8

Overcapacity for selected non-dominated solutions.

\begin{tabular}{lrrrrr}
\hline Employees & 1715 & 1931 & 2169 & 2407 & 2646 \\
\hline Profit (mill. Euro) & \multicolumn{1}{l}{68} & 67 & 64 & 59 & 46 \\
\hline & \multicolumn{2}{l}{ Overcapacity (\%) } & & & \\
\hline Cod & -5 & 10 & 23 & 38 & 45 \\
Other codfish & -15 & -11 & 1 & 14 & 28 \\
Mackerel & -1 & 0 & 1 & 2 & 8 \\
Herring & -8 & -5 & -2 & 2 & 12 \\
Shrimp and Norway lobster & -8 & 2 & 12 & 22 & 33 \\
Industrial species & -4 & -3 & 0 & 1 & 30 \\
Plaice & -5 & 6 & 13 & 23 & 37 \\
Other flatfish & -14 & -1 & 12 & 28 & 38 \\
Northern prawn & 2 & 2 & 2 & 16 & 32 \\
Mussels & 5 & 4 & 13 & 38 & 44 \\
Other species & -1 & 0 & 6 & 11 & 20 \\
\hline
\end{tabular}

These slopes thus represent the marginal loss in profit from employing another fisherman in the four intervals of the figure.

Further elaboration on such consequences is possible by relating the result to employment rate (in society). As an example, consider a situation with 2000 people employed in commercial fishery. The resulting slope would then indicate that the marginal loss in profit from employing an additional fisherman is approx. 12,605 Euro. For the fishing industry, this is obviously an undesirable prospect.. For society as a whole, however, it may be more acceptable. In 2003, the average fisherman's income in Denmark was 18,658 Euro. ${ }^{4}$ From a socio-economic point of view, revenue would increase by 18,658 $12,605=6053$ Euro. Whether this represents a value added to society depends on the shadow price of labour. If the unemployment rate is high, the shadow price will below, and vice versa. In a situation where the shadow price is below 6053 Euro, then, employing one additional fisherman would improve social revenue.

\subsubsection{Utilization of fixed capital and overcapacity}

As one moves from the profit to employment maximizing solution, the average utilization of the production units declines as there is a tradeoff in the use of fixed capital. This is illustrated in Fig. 3 by applying the measure in (13). $P$ is calculated for the nondominated solutions on the curve in Fig. 2 (from left to right). Ultimately, the preferred degree of overcapacity depends on the preferences of involved decision-maker(s). From Fig. 3 it is derived that the average utilization of fixed capital is $98 \%$ when profit is maximized, but decreases to $65 \%$ when employment is maximized.

Low capacity utilization implies overcapacity. Overcapacity, in terms of catching capability with respect to the various species, is shown in Table 8 for the non-dominated solutions of Figs. 2 and 3. Table 8 shows that overcapacity increases extensively with the desire to maximize employment. Furthermore, it appears that, with the given level of resources, it is actually preferable, from a profit maximizing perspective, with a noticeable undercapacity.

Capacity in terms of the physical inputs (gross tonnage and horse power) corresponding to the generated non-dominated solutions of Figs. 2 and 3 are depicted in Fig. 4. Noteworthy is how the inputs of gross tonnage and horse power increase as preferences towards a higher degree of employment increases.

Fig. 4 also shows the implications of including the third objective, bycatch. The two upper curves represent the situation with no restriction on bycatch, whereas the two lower curves are restricted by upper limits on the bycatch measure (Bycatch $\leq$ B). Note that including bycatch pulls the curves down. Likewise, including the

\footnotetext{
4 139,000 DKK. Account Statistic For Fishery 2005, Institute of Food and Resource Economics, Serie F nr. 11 (Table 10.1). (2006).
} 


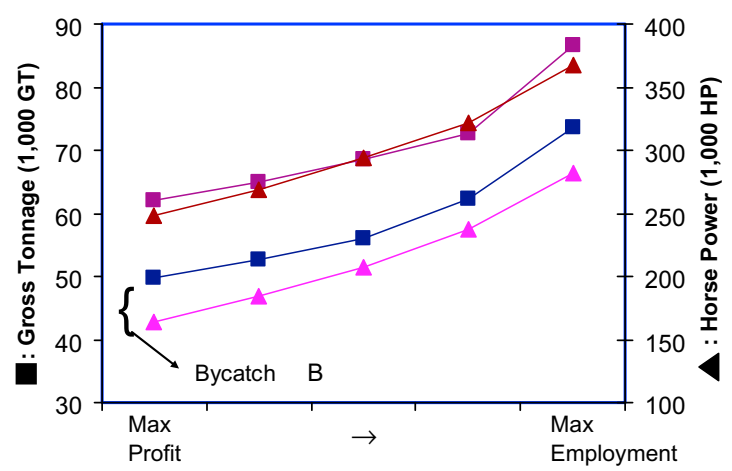

Fig. 4. Non-dominated combinations of Gross Tonnage (GT) and Horse Power (HP).

restriction on bycatch shifts the curve in Fig. 2 towards the origin. Generally, this will worsen the other objectives and reduce variation as additional objectives are included; that is to say, as more constraints are applied in the $\varepsilon$-constraint method the feasible set of solutions will be reduced.

\section{Conclusions}

Management of natural resources, including fisheries, concerns many people with a wide variety of interests. The presence of multiple objectives is most often an unavoidable reality. The purpose of this article is to contribute to the literature on industry production capacity and suggest how it can be evaluated from a multi-objective perspective.

Optimizing capacity involves the simultaneous consideration of several objectives. At the same time, it is essential to distinguish between the condition of optimal (most preferred) capacity and that situation with no overcapacity. The objectives must be traded off against one another, thus requiring management has to balance all relevant interests in determining a 'best' strategy. Unless management's preferences for lack of overcapacity are unidirectional, (single-objective optimization), degree of overcapacity will exist in the optimal solution.

A two-stage model has been suggested. The first stage is an output oriented DEA, where producers on an individual basis are compared to assess technical efficiency and production capability. In the second stage, the individual units are transformed according to the results in stage one, and included in a MCDM industry model. Combining the two stages ensures that a multiple criteria analysis takes place on the production possibility frontier. This approach was then applied to the Danish commercial fishing fleet. By generating a series of Pareto optimal solutions, tradeoffs between objectives and corresponding allocations of capacity and fleet effort were considered. Profit, employment, and bycatch were included as objectives, but other relevant objectives are likely to exist.

The model can produce valuable information for management in terms of tradeoffs, policy frontiers, objective values and optimal fleet structure. Furthermore, different scenarios can easily be structured and consequences of resulting optimal fishing fleets tested. The ease with which constraints can be changed allows for a wide range of comparative studies. For example, one could introduce a reduction in quotas, a limitation on effort, limited access to specific fishing areas, or restrictions on gear types.

Nevertheless, it is challenging to generate meaningful functional descriptions of the problem's objectives, viz., how might appropriate working conditions (safety) or damage to the ecosystem be measured?

The analysis of the Danish commercial fishery showed how optimal capacity can depend on preferences towards various management objectives. This supports the notion that fisheries inherently have some degree of overcapacity as fisheries management is generally characterised by the presence of multiple objectives. Given current quotas, the existing Danish commercial fishing fleet can thus be reduced significantly in seeking maximal profit. In this regard, as management seeks to maximize employment, overcapacity will be expected to rise.

In the present analysis, capacity measures were calculated based on current resources levels. Further, it was assumed that the output mix of a given vessel is fixed. Future research might therefore consider situations with long-term recovered stocks. Catching possibilities would likely be expanded by relaxing quota restrictions and reducing overcapacity. Conversely, allowing for changes in the output mix of individual vessels could increase potential utilization of fixed capital. In such a case, overcapacity would become even more pronounced. Finally, it would be interesting to apply the proposed model with other fleet segments, areas etc. In so doing, one could thus approach the problem of overcapacity from an international perspective, given that reliable data were available.

\section{Acknowledgements}

Kristiaan Kerstens and Niels Vestergaard contributed valuable comments and suggestions to the current analysis. Their help is gratefully acknowledged. Moreover, I am grateful for the editorial assistance from the Editor-in- Chief, Dr. Barnett R. Parker, and important suggestions from two anonymous referees. Any remaining errors are solely the responsibility of the author.

\section{References}

[1] Andersen J.L. Production economic models of fisheries: vessel and industry analysis. $\mathrm{PhD}$ thesis, The royal veterinary and agricultural university, Denmark; 2005.

[2] Briec W, Dervaux B, Leleu H. Aggregation of directional distance functions and industrial efficiency. Journal of Economics 2003;79(3):237-61.

[3] Charnes A, Cooper WW, Rhodes EL. Measuring the efficiency of decision making units. European Journal of Operational Research 1978;2(6):429-44.

[4] Charnes A, Cooper WW, Lewin AY, Seiford LM. Data envelopment analysis, theory, methodology and applications. Boston, MA: Kluwer; 1994.

[5] Chung YH, Färe R, Grosskoph S. Productivity and undesirable outputs: a directional distance function approach. Journal of Environmental Management 1997;51(3):229-40.

[6] Cooper WW, Seiford LM, Tone K. Data envelopment analysis. Boston, MA: Kluwer Academic Publishers; 2000.

[7] Dervaux B, Kerstens K, Leleu H. Remedying excess capacity in French surgery units by industry reallocations: the scope for short and long term improvements in plant capacity utilisation. In: Blank JLT, editor. Public provision and performance: contributions from efficiency and productivity measurement. Amsterdam, The Netherlands: Elsevier; 2000. p. 121-46.

[8] FAO. Managing fishing capacity: Selected papers on underlying concepts and issues. FAO Fisheries Technical Paper No. 386, Greboval, D. (ed.), Rome, FAO; 1999.

[9] FAO. Managing fishing capacity: A review of policy and technical issues. FAO Fisheries Technical Paper No. 409, Cunningham S. and Greboval D., Rome, FAO; 2001.

[10] FAO/AdriaMed. AdriaMed seminar on fishing capacity: definition, measurement and assessment. adriamed technical documents No. 13, Rome, FAO; 2004.

[11] Färe R, Grosskopf S, Valdmanis V. Capacity and efficiency in hospitals: a nonparametric approach. The Journal of Productivity Analysis 1989;1:123-38.

[12] Färe R, Grosskopf S, Kokkelenberg J. Measuring plant capacity utilization, and technical change: a nonparametric approach. International Economic Review 1989;30(3):655-66.

[13] Färe R, Grosskopf S, Li SK. Linear programming models for firm and industry performance. Scandinavian Journal of Economics 1992;94(4):599-608.

[14] Färe R, Grosskopf S, Knox Lovell CA. Production frontiers. Cambridge, Great Britain: Cambridge University Press; 1994.

[15] Färe R, Zelenyuk V. On aggregate Farrell efficiencies. European Journal of Operational Research 1994;146(3):615-20.

[16] Farrell MJ. The measurement of productive efficiency. Journal of Royal Statistical Society, Series A 1957;120(III):253-81.

[17] Frost H, Kjærsgaard J. Numerical allocation problems and introduction to the economic management model for fisheries in Denmark, EMMFID. FOI report 159. Copenhagen, Denmark: Institute of Food and Resource Economics; 2003. 
[18] Golany B, Tamir E. Evaluating efficiency-effectiveness-equity trade-offs: a data envelopment analysis. Management Science 1995;41(7):1172-82.

[19] Hardin G. The tragedy of the commons. Science 1968;162:1243-8.

[20] Jensen C.J. Fisheries in Europe - A 'tragedy of the commons' perspective. Working paper from DIFER. WP21/98 87-7780-201-2; 1998.

[21] Johansen L. Production functions and the concept of capacity. Recherches recents sur la fonction de production. Collection: Economie Mathématique et Econometrie 1968;2 [Reprinted in Førsund, F.R. (ed.), 1987. Collected works of Leif Johansen, vol. 1, Elsevier, Amsterdam, Netherlands, 359-382].

[22] Kerr CA, Glass JC, McCallion GM, McKillop DG. Best-practice measures of resource utilization for hospitals: a useful complement in performance assessment. Public Administration 1999;77(3):639-50.

[23] Kerstens K, Squires D, Vestergaard N. Methodological reflections on the shortrun Johansen industry model in relation to capacity management. Marine Resource Economics 2005;20(4):425-43.

[24] Kerstens K, Vestergaard N, Squires D. A short-run Johansen industry model for common-pool resources: planning a fishery's industrial capacity to curb overfishing. European Review of Agricultural Economics 2006;33(3): 361-89.

[25] Kirkley JE, Morrison-Paul C, Squires DE. Capacity and capacity utilization in common-pool resource industries. Environmental and Resource Economics 2002;22(1-2):71-97.

[26] Kirkley JE, Morrison-Paul C, Squires DE. Deterministic and stocastic capacity estimation for fishery capacity reduction. Marine Resource Economics 2004; 19(3):271-94.

[27] Kjærsgaard J, Andersen JL, Mathiesen Christoph. Multiple objectives and perceptions of optimal management: the Danish industrial fishery in the North Sea. European Review of Agricultural Economics 2007;34(2): $181-208$.

[28] Kjærsgaard J. Multiple criteria decision making in fisheries management: experiences and implications. Food Economics - Acta Agriculturæ Scandinavica C 2007;4(2):49-64.

[29] Lindebo E. Managing capacity in fisheries. PhD thesis, university of southern Denmark, Esbjerg, Denmark; 2004

[30] Mardle S, Pascoe S. A review of applications of multiple-criteria decision-making techniques to fisheries. Marine Resource Economics 1999;14(1): 41-63.

[31] Morrison CJ. Primal and dual capacity utilization: an application to productivity measurement in the US. automobile industry. Journal of Business and Economic Statistics 1985;3(4):312-24.
[32] Nielsen JR, Mathiesen C. Stakeholder preferences for Danish fisheries management of sand eel and Norway pout. Fisheries Research 2002;77(1):92-101.

[33] Padilla JE, Copes P. Bioeconomic analysis of management options for tropical fisheries using a bicriteria programming model. Marine Resource Economics 1994;9(4):47-66.

[34] Pascoe S, Mardle S. Optimal fleet size in the english channel: a multi-objective programming approach. European Review of Agricultural Economics $2001 ; 28(2): 161-85$.

35] Saaty T. The analytical hierarchy process. New York, NY: McGraw-Hill; 1980

[36] Steuer RE. Multiple criteria optimization: theory, Computation and application. New York, NY: Wiley \& Sons; 1986.

[37] Tingley D, Pascoe S. Eliminating excess capacity: implications for the Scottish fishing industry. Marine Resource Economics 2005;20(4):407-24.

[38] Vestergaard N, Squires D, Kirkley J. Measuring capacity and capacity utilization in fisheries: the case of the Danish Gill-net fleet. Fisheries Research 2003;60:2-3. 357-368.

[39] Yu PL. Multiple-Criteria decision making. New York, NY: Plenum Press; 1985

Jens Kjærsgaard is currently employed by the consulting firm Lohfert \& Lohfert AS in Copenhagen, Denmark. Its focus is on activity and capacity analyses related to hospital building projects. Dr. Kjaersgaard earned an M.S. in mathematical economics and operational research from University of Aarhus, Denmark, and holds a PhD in business administration from University of Southern Denmark. Prior to that, he was a researcher at the Institute of Food and Resource Economics (FOI), Frederiksberg, Denmark. He has also been employed at the consulting company COWI and engaged in severa environmental development projects (in Czech Republic, Slovakia and Ukraine) Dr. Kjaersgaard's main areas of research include bio-economic modelling and mathematical programming. Activities at FOI included participation in the development of the Economic Management Model for Fisheries in Denmark (EMMFID), and yearly calculations of economic consequences of quota proposals. Dr. Kjaersgaard has also been involved in a number of national and international projects, such as Evaluation of the pelagic ITQ (Individual Transferable Quotas) regulation in Denmark, and Multiple Objectives in the Management of EU Fisheries (EC 5th Framework Programme, QLK5-1999-01273) and EILCAM (FISH/2004/03-8). His work has appeared in European Review of Agricultural Economics, Food Economics, ICES Journal of Marine Sciences and Environmental and Resource Economics. 